\title{
Geographic imaginations: Exploring divergent notions of identity, power, and place meaning on Pha-ngan Island, Southern Thailand
}

\author{
Linda Malam \\ Department of Geography, University of Otago, Dunedin, New Zealand. \\ Email: Im@geography.otago.ac.nz
}

\begin{abstract}
This paper explores contrasting narratives of place meaning in a tourism site in Southern Thailand. Specifically, I analyse the parallel discourses of community change through tourism development embedded in international backpacker narratives, and those of the local Thai elite. By configuring identity and power around binary oppositional categories such as West as economically powerful and dominant/non-West as economically weak and subordinated, 'traditional' tourism studies often locate the dynamics of change in the international tourism industry. To date, there is little research on the very real and important ways that people working in tourism assert agency and understand their own identities in everyday contexts. I argue that local communities can, and often do, shape the changes that tourism development initiates in very creative and adaptive ways.
\end{abstract}

Keywords: host agency, power relations, Thailand, tourism

\section{Introduction}

Conceptualisations of power and identity are central to representations of people and places in the tourism literature (see: Hampton, 1998; Desforges, 2001; Tucker, 2003). There is an obvious economic hierarchy that is highlighted in the nature of the majority of international tourism - wealthy Westerners travel in their leisure time to observe and experience nonWestern places and people (Scheyvens, 2002). ${ }^{1,2}$ Coupled with the emphasis on tourism as a means of economic development by some Southeast Asian governments, it is understandable that economic power is assumed to be predominant in interactions between hosts and guests in out of the way tourist destinations. ${ }^{3}$

The conflation of economic power and personal dominance in encounters between tourists and their hosts leads to assumptions about the subjectivities of hosts, about their agency, motivations and ethics (see: Cohen, 1982; Bowman, 1989; Dahles and Bras, 1999; Herold et al., 2001; Phillips, 2002). This analytical framework relies on the assumption that if money is the basis of tourist/host interactions, then the host - who in such accounts is stereotyped as poor, underdeveloped, custom-bound - is seemingly locked into a subservient position with regard to tourists (see: Zafer Dogan, 1989; Leheny, 1995; Phillips, 2002; Smith, 2002). The inadequacy of this model of power is obvious as it ignores many other axes around which power is negotiated (Foucault, 1980); yet its influence on understandings of host/guest interactions in the media and popular discourse remains substantial.

A significant shift has been occurring among researchers with a scholarly interest in tourism whereby the agency of tourism 'hosts' is increasingly being foregrounded in studies that focus on encounters between tourists and hosts (see Scheyvens, 2002; Tucker, 2003; Doron, 2005). This trend counters the literature in which macroscale analysis of economic relations of domination and subordination have dominated the tourism studies field, obscuring the meanings that tourism hosts ascribe to their own lives and circumstances (see for example: Zafer Dogan, 1989; Leheny, 1995; Phillips, 2002; Smith, 2002). Here I extend the literature on tourism 
agency by highlighting the importance of place meaning in determining power relations in encounters between tourists and hosts.

Contemporary cultural geography's attention to multiple axes of power and the relationship between social spaces and identity provides a framework through which popular understandings of host/guest encounters can be challenged. Specifically, by representing the meanings that local people ascribe to the social and material spaces that they share with tourists, alternative interpretations of power and agency can emerge. For example, Manderson (1992) and Law $(1997,2000)$ have explored the experiences of women who work in the sex tourism industry in Southeast Asia and raised the importance of scale in mapping subjects into fields of power. They argue that by focusing the analysis at the microlevel of everyday encounters, rather than the macrolevel of political economy, a more nuanced vision of power and identity can emerge. Where much previous analysis of sex tourism had focused on the scale of political economy, where sex workers are positioned as victims of poverty, Manderson and Law have sought to draw upon the scale of the everyday, where culturally specific interpretations of place meaning can challenge narratives of the women as only-and-always victims of a wider political economy.

Importantly, this shift in focus from macrolevel to microlevel interactions acknowledges the possibility of multiple systems of meaning being overlain on a single site. As Kong and Law (2002: 1504) assert:

Plural groups, with their divergent socially constructed landscape uses and meanings, exist at times in uneasy alliance, at other times in overt conflict and, quite commonly, engage in negotiation and renegotiation of meanings on a daily basis.

Recognition of the potential for multiple systems of meaning to overlay a single site opens up the analysis of tourism-oriented spaces, expanding the focus of enquiry to include locally defined networks of meaning as well as those which are tourist-defined.

This paper contrasts two imaginaries of Koh Pha-ngan and two narratives of change. First, I focus on the development of a discourse of Koh
Pha-ngan as a site of tourist liberty and freedom to enact transgressive fantasies. Second, I focus on an alternative discourse of Koh Pha-ngan as a tightly scripted site of Thai power where tourists' transgressive behaviours are managed and contained by Thai elites. ${ }^{4}$ By analysing these conflicting discourses of place meaning, I argue that the local community on Koh Pha-ngan have adapted in highly creative ways to changes in both the social and material landscapes of their island wrought by tourism development. In particular, I contest a narrative of local victimhood and tourist dominance that is so often found in both popular and academic discourses of change through tourism development, arguing that hosts in tourism locations need not necessarily be characterised as passive recipients of change (cf: Bishop and Robinson, 1998; Dahles and Bras, 1999; Herold et al., 2001).

The data on which this article is based is drawn from a wider research project investigating encounters between migrant Thai workers and tourists in the beach bars of Koh Pha-ngan. The project included 12 months of ethnographic research in the small community of Rin Peninsula on Pha-ngan Island in Thailand's south, several subsequent visits of short (two to four weeks) duration and archival research at Lonely Planet travel guides' head office in Melbourne, the Bangkok Post newspaper in Bangkok and on the internet. This article is based primarily on informal conversations and interviews conducted in Koh Pha-ngan and the archival research in Melbourne and Bangkok. Specifically, I draw upon conversations with tourists who had visited Koh Pha-ngan during the early phases of tourism development and on informal discussions I had with members of the local Thai community about the development of tourism and accompanying social change.

\section{Transgressive space: Tourist fantasies of a tropical playground}

In international backpacker narratives about Koh Pha-ngan, the concept of marginality has been a recurring theme. ${ }^{5}$ For backpackers, Koh Phangan is a site for the enactment of transgressive behaviours - taking drugs, exploring heterosexual fantasies and participating in climactic events such as the Full Moon Party. ${ }^{6}$ These associations have their origins in the very beginning 
of tourism development on the island. In this section, I explore three 'periods' of tourism development from the point of view of international tourists, each of which configures Koh Pha-ngan as a marginal space.

\section{Koh Pha-ngan as a marginal paradise}

Koh Pha-ngan is located on the eastern side of Thailand's southern peninsula. It is Thailand's fifth largest island and has a land area of 168 square kilometres (Hongsombud, 2001). It is mountainous, with nine peaks above 378 metres, the highest measuring 627 metres above sea level. Over $70 \%$ of the island's land area is mountains and tropical forest (Hongsombud, 2001; Westerhausen, 2002). The interior of the island is heavily forested with only a few access roads. The island's fresh water supply is sourced from the numerous rivers that flow down from the mountains. Koh Pha-ngan has 36 beaches, many with stunning granite headlands and sand dunes covered in coconut trees (Hongsombud, 2001). There are several coral reefs around the island with an abundance of marine life (see Fig. 1). Koh Pha-ngan first emerged in discourses circulating among international backpacker tourists in the early-mid 1980s. At that time, the island was configured as a marginal space by international backpackers both geographically and socially - it was not easily accessed, requiring a ferry trip from the mainland via a route that was not part of a well developed tourist circuit. Moreover, the island's physical beauty meant that it resonated with images of a 'lost paradise island' abundant in the literary traditions and popular press in the backpacker's countries of origin, such as the novel Robinson Crusoe by Daniel Defoe, or the movies The Beach and Blue Lagoon.

Socially, the island was configured as marginal in international backpacker discourses because it was not part of a well known tourist route and because it was known as a site where marijuana was freely available. The local people on the island have been very permissive of tourists' behaviours with regard to drugs and the island became famous as a site of freedom of expression (Westerhausen, 2002). Accessible by boat, Haad Rin peninsula was the favoured tourist destination on Koh Pha-ngan, as it was a place where tourists could take drugs quite freely without fear of arrest. Police could not easily stage surprise drug raids as they relied on a slow boat trip to get to the peninsula from the main port town of Thongsala. Throughout the 1980s, it was very common to buy packets of marijuana in almost any restaurant in Haad Rin, and not uncommon to smoke marijuana on the street or on the beach without fear of arrest (field notes, 2001). Magic mushrooms were another freely available drug and featured on most restaurant menus in 'special' omelettes, milkshakes or teas (and still do in some bars and restaurants). This permissive social milieu was to prove central as tourist images of Koh Pha-ngan transformed and tourism development boomed (See Box 1).

\section{Koh Pha-ngan as a hedonistic party space}

In the final years of the 1980s, there was a distinct shift in the ways that Koh Pha-ngan was configured in international backpacker discourses - as a narrative of marginality gave way to one of transgression. The emergence of an international rave party scene and its conflation with backpacker travel meant that there were new kinds of tourists coming to the island. Tourists who emerged from the rave scene were travelling for much shorter periods of time because travelling for them was an activity done during time off from university or work, not a perpetual lifestyle as with many of the earlier tourists to the island.

In 1988, the first Full Moon Party occurred, an event that would greatly influence the course of tourism development in Koh Pha-ngan. A local Koh Pha-ngan man, Suddhi Gueasakoon, staged a beach party for a group of friends and guests featuring the latest dance/rave music from Europe (field notes, 2001). Approximately 50 people attended that first party and it was a great success in terms of being an enjoyable event where people could get together and take in the scenery of the bay and the music. The positive response from people who had attended that first party gave local people the idea of staging regular parties at full moon time. While commercial considerations would likely have been part of the decision to continue the parties on a regular basis, it is unlikely that anyone involved in those first parties could have envisaged the commercial opportunities that the parties would generate in the following years. 


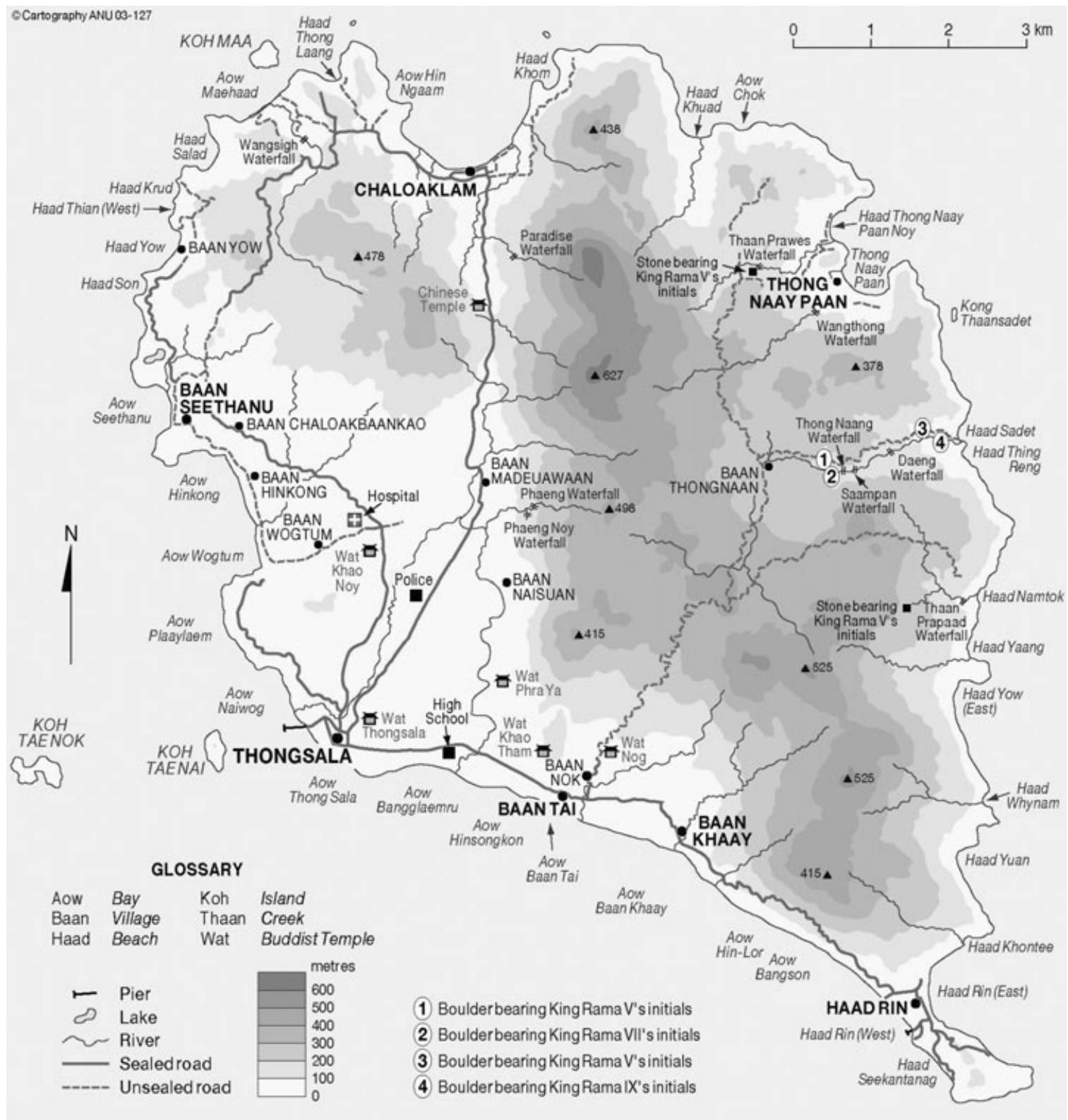

Figure 1. Map of Koh Pha-ngan

Source: Australian National University Cartography Department.

The inception of the Full Moon Parties coincided with the development of an international rave party culture associated with an avantgarde cachet (Saldanha, 2007). This party culture incorporated a following of and interest in new and experimental techno music and the ingestion of a variety of party drugs such as ecstasy, cocaine and amphetamines. Alcohol was not a favoured drug of choice. According to Westerhausen (2002), a combination of factors including crackdowns on the tourist drug and party scene in Goa, a burgeoning rave community in Europe and America eager to find new venues for staging rave parties, as well as the lack of policing on Koh Pha-ngan where tourists could take drugs and party with little interruption all coalesced around the time of the first Full Moon Party. This combination of factors meant that once Suddhi Gueasakoon initiated the monthly Full Moon Party event, the party, 


\section{Box 1. Reporting drugs on Koh Pha-ngan in Lonely Planet Guides}

The first edition of Lonely Planet Thailand, published in February 1982, features only two sentences on Koh Pha-ngan as an adjunct to information on Koh Samui. Pha-ngan's deserted beaches and coral formations are listed as features, but no accommodation is mentioned as being available. By the time the third Lonely Planet Thailand edition was published in January 1987, the section on Koh Pha-ngan had expanded to one and a half pages, featuring information on accommodation, transport and tourist attractions. Pha-ngan was described as 'like Samui ten years ago' with an 'overall less-spoiled atmosphere' (p. 231).

The first mention of illegal drugs (and the Full Moon Party) came in Lonely Planet Thailand's fifth edition, published in October 1992, where reporting of 'the famous monthly full moon parties featuring all-night beach dancing and the ingestion of various illicit substances' signals the beginning of widespread recognition of the permissive social milieu for tourists on Koh Pha-gnan. By the time the sixth edition was published in 1995, reporting of drugs on the island had taken the form of warnings to tourists. In the general 'Facts for the Visitor' section under the sub-heading 'Drugs', the following anecdote provides a stark warning to tourists: 'I've heard one confirmed story of a falang (white tourist) who swam to his death off Koh Pha-ngan after a "special" mushroom omelette' (p. 123).

This tone of warning with relation to drugs on the island was further expanded in following editions, with special sections on 'Dangers and Annoyances' featuring advice on avoiding arrest for consuming marijuana while on Koh Pha-ngan. Hallucinogenic drugs are also strongly featured in the double page boxed text on 'Surviving the Hat Rin Full Moon' (appearing from the eighth edition in 1999 onward). While the advice published in Lonely Planet warns tourists about potential dangers associated with taking drugs on Koh Pha-ngan this widespread dissemination of information about the ready availability of drugs would likely have had the dual effect of alerting tourists who were interested in taking drugs that it was possible to do so on the island and warning other, more wary tourists of the potential dangers of this activity.

and the amount of tourist interest in Haad Rin Peninsula, were set to grow exponentially. At that time in 1988, tourism had not yet boomed on the island. From an initial 50 partygoers in 1988 , by 1999 the number was estimated to be up to 30000 at peak times.

From around 1989, international newspaper reports began to express moral outrage at the drug and party culture evident on Koh Pha-ngan and in the process inscribed an image of the island as a site of hedonistic abandon (Westerhausen, 2002). The following excerpt from the Bangkok Post is illustrative of the types of reports that were being published:

\section{Mental hospital braces for influx of loony falangs}

Bangkok Post, November 161994

The South's biggest mental hospital was last night preparing for the arrival of a number of falangs ${ }^{7}$ who are expected to overdose on drugs at tomorrow's Full Moon Party on Pha-ngan Island.

Suan Saranrom ('Garden of Joys') psychiatric hospital in Phun Phin will have cases referred to it by the tourist police who are expecting to pick up the young falangs during or in the immediate aftermath of the party.

Hospital director Kamthorn Pringsulaka said the most common problem among incoming falangs was that associated with 'magic mushrooms', LSD and other hallucinogens available in plentiful quantities on the island.

The hospital treats the falangs for an average of seven days with antipsychotic drugs. The symptoms on arrival include over-excitement, overactivity, a mood of heightened irritation and extensive visual and auditory hallucinations ...

Newspaper reports such as these alerted potential tourists who were interested in this type of 


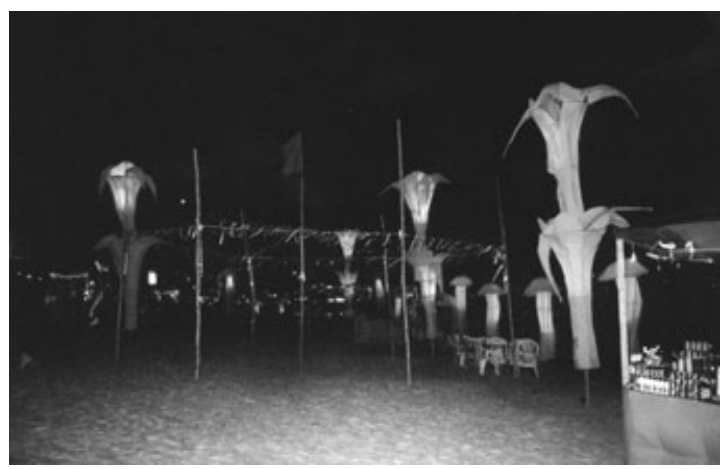

Figure 2. Full Moon Party decorations transform the beach

Source: Linda Malam.

tourism experience to the island's existence and therefore increased tourism numbers. They also alerted concerned citizens and foreign governments to the fact that their children/ grandchildren/citizens were participating in a 'risky drug culture' while overseas. ${ }^{8}$ The emergence of narratives of moral outrage about the parties on Koh Pha-ngan and the drug use that went along with them was a precursor to greater police presence and increased attention to the policing of drugs on the island.

The Full Moon Party scene emphasised Haad Rin as a carnivalesque space, complete with costumed and body painted participants, lurid sculptures erected on the beach and special lighting (Fig. 2). Full Moon Party night is a time when things that are 'out of the ordinary' can happen. Since the inception of the Full Moon Party as a regular event on Koh Pha-ngan, the island, and Haad Rin in particular, has been firmly inscribed in international backpacker circles as a hedonistic party space.

\section{Koh Pha-ngan as a mainstream party island}

From about 1995 onward, the image of Koh Pha-ngan started to shift again. By that time, Haad Rin and Koh Pha-ngan had been so widely reported in the international media and in guidebooks that there were huge numbers of tourists coming to the island. ${ }^{9}$ Because of the increased numbers and the enlarged sections of guidebooks that were devoted to describing Koh Phangan, the island started to get a reputation for being more of a 'mainstream' tourist destination.
Exact numbers of tourists are difficult to know, but one can estimate from the proliferation of bungalow accommodation that tourist numbers had increased dramatically. The Tourism Authority of Thailand started monitoring tourist arrivals to Koh Pha-ngan in 1999. In that year, there were 138906 tourist arrivals. In 2000, there were 154042 and in 2001, there were $157865 .^{10}$ By 2007, tourist arrivals had increased to 284879 (Tourism Authority of Thailand statistics division, http://www2.tat.or.th/stat/web/static_tst.php).

According to long-term resident expatriates in Haad Rin, backpacker tourists still came to Haad Rin but they were no longer part of the community of tourists who stayed for extended periods of time in Southeast Asia, nor were they the same as the initial dance-party-focused raver groups. They were increasingly young blue-collar workers who were on holidays for two weeks or a month, as well as university students on annual holidays.

In contemporary Koh Pha-ngan, the place meaning of the island as a site of transgression lingers on, yet it is no longer identified with the 'drifter tourists' or the rave party avantgarde set as in earlier periods (Cohen, 1982). While the popular party drugs (ecstasy and amphetamines) are still widely available, the dominant drug used by tourists on the island is now alcohol. The changing meaning of Koh Pha-ngan, from marginal paradise to hedonistic party site to mainstream backpacker tourist destination, is reflected in the material and symbolic landscapes and in a variety of texts about the place. In 2002, Student Travel Association travel, the world's largest student, youth and budget travel organisation, named Koh Pha-ngan's Full Moon Party in a feature on the 'World's top 5 party spots'. This recognition reflects both the efficacy of the narratives of transgression that had been circulating in the backpacker scene about Koh Pha-ngan and its transformation from an intrepid tourism destination to a mainstream backpacker site. STA's Go Mag has massive distribution (it is available in STA offices across the globe). The ability of such a publication to shape tourists' expectations about travel destinations and travel itineraries is therefore considerable (see Fig. 3).

The contemporary material landscape has changed dramatically since the early years of 


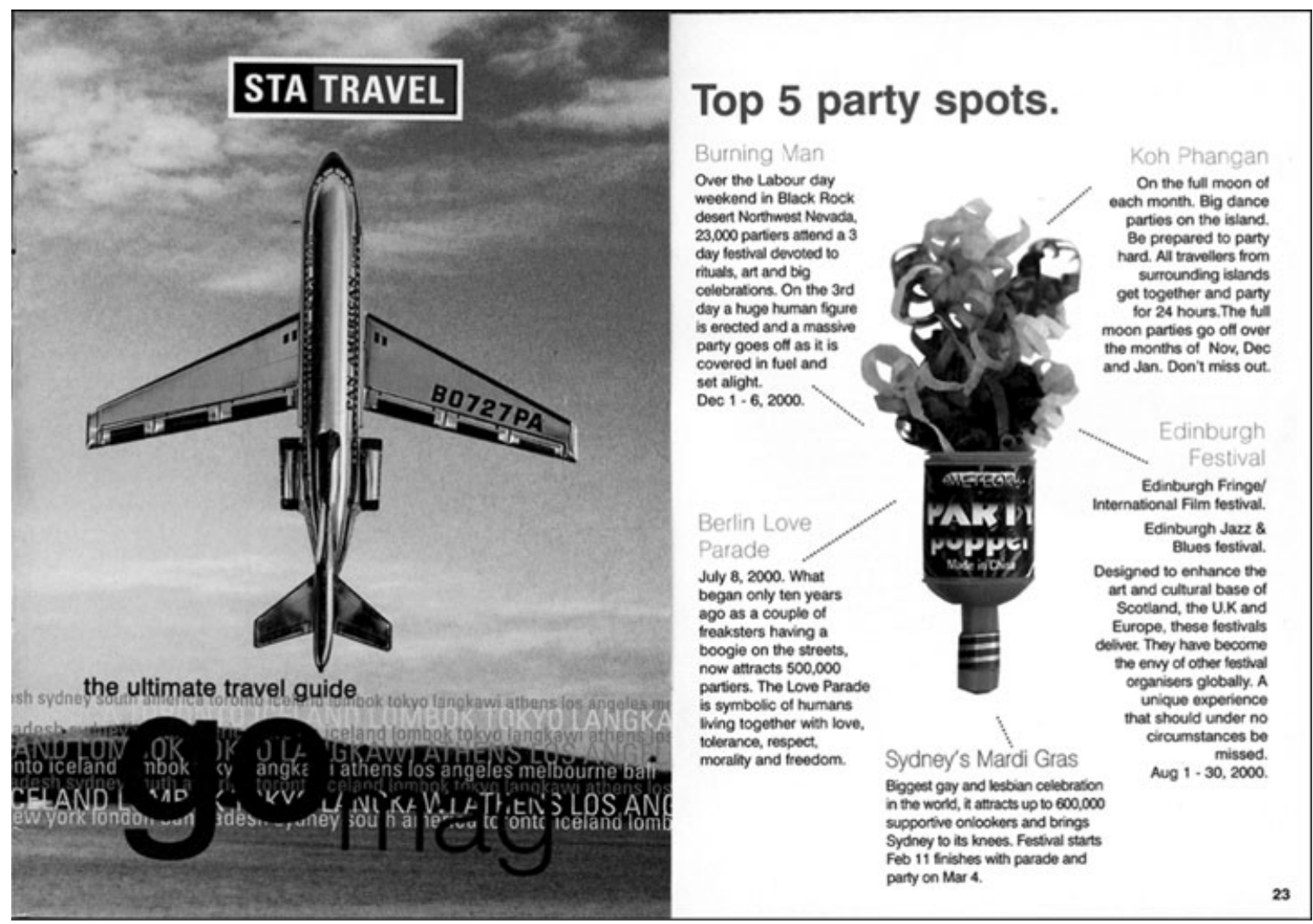

Figure 3. Student Travel Association Go Mag (2002)

tourism on the island. On my first visit to Haad Rin in 1994, the tourist infrastructure consisted of bamboo thatch bungalows and restaurants sparsely placed in an open coconut grove. The transformation from 1994 to 2000 when I returned to begin fieldwork was so great that it was barely recognisable as the same place. As Figure 4 illustrates, the landscape of Haad Rin is now dominated by concrete buildings offering accommodation and tourist services.

A focus on a particular type of entertainment bar-based socialising - is also evident in the domination of the material landscape by bars and clubs. The predominance of bars on the main beach is the material manifestation of the shift in the preferred drugs of the tourists coming to the island. In earlier periods of tourism development, partying was either focused around gatherings on the beach where acoustic music was played or in the monthly rave parties, which were also staged on the beach. Now, the bars are the locus of tourist socialising. The bars play a mixture of many types of techno music, but the

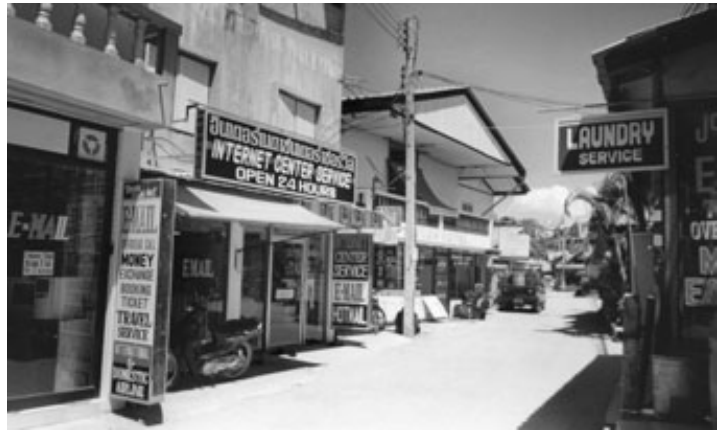

Figure 4. The main street of Haad Rin Source: Linda Malam.

most popular bars play mainstream pop music from Europe and the US. Many bars try to capitalise on the cachet of the Full Moon Parties by staging Half Moon Parties and Black Moon Parties; but these events resemble regular nights out at a bar drinking alcohol rather than the nights of carnivalesque transgression and party drug ingestion that characterise the Full Moon Parties. The focus of the bar scene is clearly on 


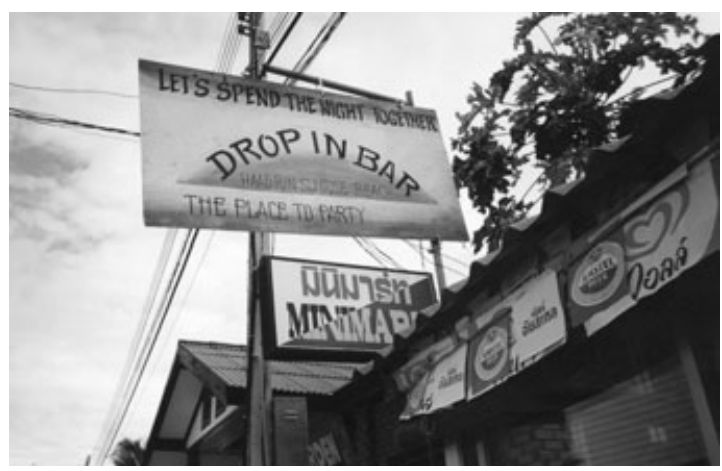

Figure 5. Drop In Bar advertising: 'Let's spend the night together'

Source: Linda Malam.

the consumption of alcohol and the expression of heterosexual desire. The ambiguous wording on the sign (see Fig. 5) advertising on one of the bars leaves open the suggestion of sexual liaisons - customers are encouraged to 'spend the night together', a phrase that is often used as a euphemism for sexual encounter. While there is nothing here to signify that the bar is a site for heterosexual desire and fulfilment, exclusionary practices in the bar whereby homosexual men are often harassed and marginalised by bar staff effectively enforce the vision of the space as excluding homosexual desire (see Malam (2008) for a more detailed discussion of this issue).

Throughout the three periods of tourism development described here, the themes of social transgression and geographic marginality have been predominant. In the material, symbolic and verbal constructions of Koh Pha-ngan, a narrative that highlights tourists' liberty and freedom to enact their transgressive drug and (hetero)sexual fantasies, is clearly evident. The 'transformation' of Koh Pha-ngan from a quiet island with a small local population to the busy, built-up backpacker Mecca that it is today could be interpreted as evidence of a breakdown of local culture, a sign of Western penetration of and dominance over yet another 'out of the way' place (Tsing, 1993). The image of the island as a 'party site' and playground for tourists in particular, plays into narratives of destruction of local culture (Zafer Dogan, 1989; Leheny, 1995; Phillips, 2002; Smith, 2002; Westerhausen, 2002). However, to focus only on tourists' constructions of place meaning would be to eschew other important and alter- native constructions of place meaning. As Del Casino and Hanna (2000) have argued, tourism spaces always contain within them the dominant identity, the tourist, and its submerged other, the non-tourist. Non-tourists perform as part of the site, and therefore reproduce the tourism space in ways they determine.

I now turn to examine another narrative of place meaning, from the point of view of local Koh Pha-ngan people. Highlighting locally defined meanings of Koh Pha-ngan allows a very different narrative of agency and identity to emerge than is possible when only touristfocused accounts are represented. Local interpretations of social and economic change encompass a keen awareness of the economic benefits that tourism can offer and an ability to see tourists as just one of a number of 'others' with whom local elites engage in order to balance the complex social system of the island for their own social and economic gain.

\section{Containing transgression: Thai narratives of power and governance}

As well as being part of a tourist narrative, tourism spaces are constructed and crafted by local elites (Urry, 1990; Boyle and Hughes, 1991; Kearns and Philo, 1993; Shields, 2003). Hanna et al. (2004) have argued that local elites attempt to direct and manage the development of place image through controlling the key channels through which place meanings are disseminated: representations and texts about place, the built environment and the performances of tourism workers. In this section, I trace the ways that local elites on Koh Pha-ngan have fostered the development of the island as a site of transgressive tourist liberty. Here I highlight a very different interpretation of social and economic change than those found in international backpacker narratives. In focusing on the construction of the tourist site, I locate the power to define and shape place meanings with the local elites, not the tourists. Importantly, the existence of this alternative narrative is not posed as a challenge to the island's hegemonic identity as a tourist playground.

In contrast to tourist's imaginaries of Koh Phangan, which largely focus around the island's apparently permissive social milieu, members of the local Koh Pha-ngan community imagine 
the island primarily in terms of relationships between social groups, hierarchy and governance. Understandings of local hierarchies and power networks between families are integral to Koh Pha-ngan locals' imaginings of place. Local power networks have always been very important to Koh Pha-ngan people because these power networks served as the form of governance on the island prior to the introduction of Central Thai instruments of government such as police and judicial systems. Local power networks overlay the landscape determining who has access to which land, who has access to marine resources, who is able to run businesses and where (e.g. in cases where new businesses compete with existing ones belonging to members of powerful families). Local people and others who live on the island permanently have a very highly developed sense of where they feature in this power hierarchy, and this knowledge dictates the ways that they use and move around in the landscape. Here I detail some of the key shifts in local power constellations and governance networks in order to highlight the agency of local people in directing social and economic change on Koh Pha-ngan.

\section{Tourism - a space of opportunity for a new local elite}

Prior to, and in the early stages of tourism development, Koh Pha-ngan was configured as remote from central Thai governance and its 'rule of law' enforced by police, local councils and elected government officials. While the local village head is linked to the Central State governance system through a chain of responsibility, in practice, the Central State had very little influence over daily decisions and local level governance processes because of the lack of communications technology and infrastructure linking Koh Pha-ngan with the Thai mainland. ${ }^{11}$ Like residents in many other areas within the Thai state that were in some way remote, Koh Pha-ngan residents have developed their own form of local governance, presided over by the local elite (Ockey, 1998). This local elite was constituted of men from economically powerful families, usually landholders who had access to economic power, which, prior to tourism development, was linked to agricultural production. By the early 1990s, this economic power was largely drawn from income related to tourism businesses and linked to beachside land.

During these early years of tourism development, the incorporation of tourists into local social structures was relatively unproblematic. Relationships between tourists and local people were very informal, with tourists often staying in local peoples' homes at no cost and engaging in cultural exchange and friendship. There were few overt conflicts between tourists and local people and therefore little motivation for local people to see themselves in governance roles with respect to tourists. Tourists' behaviours were not so different from those of local people in several respects. First, they were accommodated in simple bungalows or locals' homes with no electricity and so did not use considerably more energy than local people. Second, they ate in restaurants that provided mainly local fare and so did not require local people to develop complicated trade connections with mainland Thais. Third, while many of the tourists did take drugs more publicly than local people would, the drugs they took were the same ones that local youths occasionally used and they were locally grown and distributed (such as magic mushrooms and marijuana). All of these factors meant that there was little reason for overt conflict between tourists and local people, and local people did not need to see themselves as playing strong governance roles with regard to tourists. This would change as tourism development increased.

\section{Emergence of a new tourism-based elite and the island as a space of control}

Anecdotal evidence suggests that the number of people on the island expanded rapidly in the period between the late 1980s and mid-1990s. Tourism numbers had skyrocketed (Westerhausen, 2002), as had numbers of predominantly young male migrants who came to staff the burgeoning tourism businesses. Because of tourism development, the social system on the island was becoming increasingly complex, incorporating a substantial migrant population, representatives of the central Thai state, tourists and entrepreneurs from both the Thai mainland and elsewhere (primarily Europe, America and Australasia). In terms of governance, the local elite needed to find ways of managing this 
increasing and diversifying population. They did this by developing strategic links with representatives of the Thai central state (such as police), and by tightly monitoring and controlling the behaviours of both migrant labour groups and tourists. Here I detail the positioning of two key groups, bar workers and tourists, with relation to the local elite in order to highlight the centrality of local elites in crafting the image of Koh Pha-gan as a site of tourist transgression and freedom.

Bar workers on Koh Pha-ngan (and in many other tourist epicentres) comprise a separate and distinctive subgroup within the migrant labour force in Thailand, and are recognised as such by the local people on Koh Pha-ngan. These workers are just one of the migrant worker communities on the island, but they are the most visible, spatially mobile and problematic for the local community. They are easily differentiated from other migrant groups by their style of dress, behaviour, use of public and private spaces, and by their places of work. Bar workers usually dress in a rebellious youth style, are often drunk in public and also frequently initiate brawls in the bars and occasionally on the streets. In particular, violent altercations between bar workers and male tourists are a clear threat to tourist imaginaries of the island as a 'tropical paradise' as are incidents of date rape and drugging of female tourists, both of which occurred on a regular basis during the time I conducted fieldwork. Without intervention by local elites, such incidents would likely have been much more frequent. It is these behaviours that set migrant bar workers at odds with the local community because they contravene acceptable codes of behaviour and threaten the tourism industry. These migrant workers are tightly governed by local elites through complex processes of surveillance, warnings for social transgressions and punishments. Containing and managing the violence that these workers occasionally exert on tourists is a very important aspect of maintaining foreigners' imaginaries of the island as a marginal paradise and a relaxed and enjoyable holiday destination.

By the mid 1990s, increases in the number of tourists visiting the island and changes in the tourism culture whereby bar-based socialising had become the primary pastime meant that relationships between local elites and tourists had changed considerably from earlier periods. Increasingly, tourists were seen as a group that needed to be humoured and protected from negative experiences (such as violence from migrant workers) and kept ignorant of local power hierarchies and government methods. Because many tourists do not have the language skills or cultural knowledge required to perceive the complexity of Thai social status and organisation, they sit almost in a separate social space, unaware in many instances of the power networks shaping and channelling their experiences of the people and places they are visiting. An event that happened during the time I was in Haad Rin illustrates the existence of diverse social spaces in the same site very well. It was related to me by an expatriate business owner who had witnessed it as it unfolded.

\section{A clash of place meanings}

On a steamy Sunday afternoon a member of the local elite who held considerable influence in the community was in front of his house smacking his grandson. This was an unusual occurrence; it is generally not normal practice for children to be beaten, so there must have been a very serious cause for this public display of punishment. No Thai people intervened in this event, for two main reasons. First, the man doing the beating was a very respected and revered man in the community and to intervene would be to insinuate that his punishment was unjust or inappropriate. Second, even if the man was not a highly respected member of the local elite, it would still be a great insult for another Thai person to interfere in an action that would be understood as private family business. Again, such an intervention would be seen as a great insult to the head of the household dealing out the punishment.

A female Israeli tourist who saw the man beating his grandson strode across the road and pushed the man to the ground, shouting abuse at him for beating the child. The man could not stand for this - a female tourist pushing him to the ground and interfering in his just punishment of his grandson was a serious transgression of the Thai social order. His reaction was extreme. He stood up, pulled a pistol from his trousers and held it to her head while shouting at her in Thai. After a few minutes, when it was clear that the woman 
was terrified (she was screaming and shaking uncontrollably) he let her go and she ran off. The police were never involved in the incident. I do not know if the woman reported the incident, but in any case the police would never have approached the man over this matter.

For the Thai people of the area, this man's identity in the Thai social space means that he is beyond reproach in matters of his family and how he deals with them. He is also an older person, who is worthy of respect and is protected from public criticism by cultural codes of respect. For the tourist woman who intervened in the beating, the man's identity was perceived very differently. She perhaps saw him as a cranky old man, unjustly beating a defenceless child. Whatever her perception of this man was, there was no sense of his position in the Thai community in it.

Incidents like this, where tourists and local elites come into direct conflict, are relatively rare. Tourists are not usually publicly shamed or beaten, because, for the most part, their interests do not conflict with those of the local elites. There have, however, been several incidents where local people have publicly punished tourists for gross transgressions of the perceived social order, such as when a tourist endangers the lives of others through reckless action (e.g. by lighting a large firecracker inside a crowded bar) or physically attacks another tourist. The delineation of jurisdiction over incidents like this as belonging to the local elites rather than the local police is something clearly recognised by local police, who do not intervene when local elites seek to punish tourists in this way. The integration of the local governance system with that of the Thai State was another significant social shift in Koh Pha-ngan over the past two decades.

As Ockey (1998) has argued, political culture develops at different rates in different places. He asserts that in Thailand, conceptions of law and democracy based on Western notions are much more established in the centre (in Bangkok, and in important provincial cities) than they are in the periphery. In peripheral locales such as Koh Pha-ngan, non-State governance systems often coexist with official State governance systems. That is, local people often develop, for example, their own versions of a judicial system, with community members meeting to discuss behavioural transgressions and deciding on appropriate punishments, or economic and social regulatory systems where community leaders make decisions on who can have access to a particular land in the area, or who can open up new businesses and so on.

This picture of Koh Pha-ngan as a space at the centre of complex power networks and governance procedures presided over by the local elites in conjunction with Thai government officials is in stark contrast to the island's image as a tourist playground in backpacker circles. Local elites are the centre of a complex social system that is comprised of not only local Koh Pha-ngan people but also various migrant groups (including government officials and police) as well as international tourists. Each of these groups brings a variety of values and mores about appropriate behaviours in the tourist site. Keeping the sometimes competing visions of place meaning in concord requires an overall vision of how all the pieces of this social jigsaw fit together. Because of the role that local elites play as managers of the tourist site, their vision of place is therefore very different to the dominant tourist vision, as outlined in the first section of this paper.

\section{Conclusion}

In this paper, I have traced the development of the hegemonic discourse of Koh Pha-ngan as a particular type of leisure site: a tourist space where transgressive behaviours are the norm. I have detailed discursive and symbolic aspects of place meaning and demonstrated that the meaning of the place is intimately connected to the subjectivities that are enacted within it. I have also examined the work that maintains the hegemonic narratives of Koh Pha-ngan as a transgressive leisure site. I have argued that the tourist sites on Koh Pha-ngan, and Haad Rin in particular, are zones of careful scripting and management, presided over by local elites.

Over the past two decades, as tourism development has increased, it is clear that local peoples' imagining of the island space had shifted. In the early years of tourism development, the island was imagined as a space of opportunity that was relatively unproblematic in governance terms. Later, the imaginary shifted 
to conceptualise the island as a space that local elites needed to govern in order to control the behaviours of the new members of their community, especially the migrant workforce. Local people increasingly came to see themselves as caretakers and protectors of tourists, a role that is evidenced in the type of language used to describe tourists; local elites jokingly referred to tourists numerous times during interviews as sat anurat (protected species). This term is used not so much as a derogatory term (although it could be read as derogatory because, strictly speaking, sat is a classifier used for animals, not people), rather, it refers more to the role of local elites in carefully controlling the various migrant groups in order to humour the tourists with their vision of tourist power and liberty on the island. By focusing on locally defined interpretations of social and economic change, a nuanced vision of power relations between tourists and hosts emerges which poses a clear challenge to notions of tourist dominance of local people found in the tourism literature.

\section{Acknowledgements}

I would like to thank the people who gave their time to participate in this research and the journal reviewers and editors for comments on earlier drafts of this paper.

\section{Notes}

1 I wish to signal my discomfort with the unproblematic use of the West/non-West binary here. This way of dividing the world into two distinct categories is a social construction and is therefore open to contestation. I mobilise these terms conditionally in this analysis in order to be able to focus on the discursive construction of power and identity that is integral to the separation of these categories.

2 Westerners are not the only ones to participate in global tourism - wealthy Thais also travel to Europe and Australia to see 'weird' kangaroos, the Gay Mardi Gras and so on. In this sense, I focus only on the majority of international tourism to out of the way countries, that being Western tourists.

3 I use this term to refer to places that have been variously labelled as the Third World, Developing and/or Underdeveloped countries. Out of the way places was a term first coined by Tsing (1993). This term is an attempt to step outside of narratives of power that are imbued in the more commonly used labels mentioned above. 'Out of the way' refers to places that have been discursively marginalised in global hegemonic discourses of centre and periphery.

4 I use the terms Thai/local elites in this paper to refer to men from local Koh Pha-ngan families who own businesses or are otherwise positioned in the locally based governance system of the island. There is a distinct regionalism to identity on Koh Pha-ngan which positions locally born people at the top of the hierarchy of island inhabitants. Gender also plays a role with men positioned as the public face of leadership in many Thai communities, to which this is no exception.

5 Evidenced in archival research of Lonely Planet travel guides on Thailand between 1982 and 2007.

6 Pha-ngan Island is famous in backpacker circles for its monthly Full Moon Parties, huge outdoor rave events that attract around 10000 partygoers each month.

7 This is a Thai term, a variation of falangs, used to refer to people of Anglo-Saxon origin.

8 The original reports in the Bangkok Post were occasionally picked up and republished by newspapers in both Europe and the United States.

9 In 1995, Lonely Planet Thailand featured a seven-page section on Koh Pha-ngan and described the island as the island of choice for those who find Samui too crowded' (p. 662). This when compared with the amount of coverage Koh Pha-ngan received in the first Thailand Edition in 1982, where only one paragraph on the island appeared, shows the huge growth in the popularity of the island and its representation in backpacker guides.

10 Tourism Authority of Thailand, in an email on 04 March 2004, detailing the number of tourism arrivals on Koh Pha-ngan.

11 The local elite, (headed by the phuyai ban (village head) ) are theoretically a part of the Central Thai governance system, with the phuyai ban being answerable to the kamnan (subdistrict head) who is answerable to the nai amphur (district head). The nai amphur (district head) is a full-time public official, while, on Koh Phangan, the phuyai ban (village head) and the kamnan (subdistrict head) hold other livelihoods at the same time as exercising the duties of local governance.

\section{References}

Bishop, R. and L.S. Robinson (1998) Night market: Sexual cultures and the Thai economic miracle. New York: Routledge.

Bowman, G. (1989) Fucking tourists: Sexual relations and tourism in Jerusalem's old city, Critique of Anthropology 9(2): 77-93.

Boyle, M. and G. Hughes (1991) The politics of representation of the 'real': discourses from the left on Glasgow's role as European city of culture, Area 22: 217-228.

Cohen, E. (1982) Marginal paradises: Bungalow tourism on the islands of Southern Thailand, Annals of Tourism Research 9(2): 189-228.

Dahles, H. and K. Bras (1999) Entrepreneurs in romance tourism in Indonesia, Annals of Tourism Research 26(2): 267-293. 
Del Casino, V.J. Jr and S.P. Hanna (2000) Representations and identities in tourism map spaces, Progress in Human Geography 24(1): 23-46.

Desforges, L. (2001) Tourism consumption and the imagination of money, Transactions of the Institute of British Geographers 26(3): 353-364.

Doron, A. (2005) Encountering the 'other': Pilgrims, tourists and boatmen in the city of Varanasi, Australian Journal of Anthropology 16(2): 157-178.

Foucault, M. (1980) Power/knowledge. Brighton: Harvester.

Hampton, M.P. (1998) Backpacker tourism and economic development, Annals of Tourism Research 25(3): 639660.

Hanna, S.P., V.J. Del Casino Jr, C. Selden and B. Hite (2004) Representation as work in 'America's most historic city', Social and Cultural Geography 5(3): 459-581.

Herold, E., R. Garcia and T. De Moya (2001) Female tourists and beach boys: Romance or sex tourism? Annals of Tourism Research 28(4): 978-997.

Hongsombud, V. (2001) Guide Map of Koh Phangan and Koh Tao. Bangkok: V. Hongsombud.

Kearns, G. and C. Philo (eds.) (1993) Selling places: The city as cultural capital, past and present. Oxford: Pergamon.

Kong, L. and L. Law (2002) Introduction: Contested landscapes, Asian cities, Urban Studies 39(9): 1503-1512.

Law, L. (1997) Dancing on the bar: Sex, money and the uneasy politics of third space, in S. Pile and M. Keith (eds.), Geographies of resistance, pp. 107-123. London: Routledge.

Law, L. (2000) Sex work in Southeast Asia: The place of desire in a time of aids. London: Routledge.

Leheny, D. (1995) A political economy of Asian sex tourism, Annals of Tourism Research 22(2): 367-384.

Malam, L. (2008) Spatialising Thai masculinities: Negotiating dominance and subordination in Southern
Thailand, Social and Cultural Geography 9(2): 135150.

Manderson, L. (1992) Public sex performances in Patpong and explorations of the edges of imagination, The Journal of Sex Research 29(4): 451-475.

Ockey, J. (1998) Crime, society, and politics in Thailand, in C.A. Trocki (ed.), Gangsters, democracy and the State in Southeast Asia, pp. 39-53. Ithaca, New York: Southeast Asia Program, Cornell University.

Phillips, J.L. (2002) The beach boys of Barbados: Postcolonial entrepreneurs, in S. Thorbek and B. Pattanaik (eds.), Transnational prostitution: Changing patterns in a global context, pp. 42-56. London: Zed Books.

Saldanha, A. (2007) Psychedelic white: Goa trance and the viscosity of race. Minneapolis, Minnesota: University of Minnesota Press.

Scheyvens, R. (2002) Tourism for development: Empowering communities. Harlow: Pearson Education Limited.

Shields, R. (2003) Political tourism: Mapping memory and the future of Quebec City, in S.P. Hanna and V.J. Del Casino Jr (eds.), Mapping tourism, pp. 1-27. Minneapolis, Minnesota: University of Minnesota Press.

Smith, C. (2002) Backpackers Inc. The Sydney Morning Herald (Travel Section), 8-9 June, pp. 1-4.

Tsing, A.L. (1993) In the realm of the diamond queen: Marginality in an out-of-the-way place. Princeton: Princeton University press.

Tucker, H. (2003) Living with tourism: Negotiating identities in a Turkish village. London: Routledge.

Urry, J. (1990) The tourist gaze: Leisure and travel in contemporary societies. London: Sage Publications.

Westerhausen, K. (2002) Beyond the beach: An ethnography of modern travellers in Asia. Bangkok: White Lotus Press.

Zafer Dogan, H. (1989) Forms of adjustment: Sociocultural impacts of tourism, Annals of Tourism Research 16(2): 216-236. 